leprosy feasible, permitting early treatment to reduce its transmission and prevent the development of nerve damage and deformity.

As resistance to leprosy is provided by cell-mediated immunity ${ }^{1}$, the availability of antigens produced by recombinant DNA technology should allow experiments to be performed to address the basic immunological question of whether epitopes recognized by monoclonal antibodies are also recognized by $T$ cells. In addition, a mixture of peptides recognized by helper $\mathrm{T}$ cells could, for the first time, provide a specific skin test antigen for use in assessing the immunological status of patients and their contacts-this is urgently needed to permit rapid evaluation of the immunological efficacy of the candidate vaccines against leprosy that are being developed ${ }^{15}$. Finally, the identification of antigens involved in cellular immunity could lead to the development of a new generation of vaccines. Because of the intrinsic adjuvant properties of mycobacteria, one attractive approach is to introduce genes whose products provide protection into cultivatable mycobacteria, to produce a vaccine capable of engendering long-lasting cell-mediated immunity.

We thank D. Young, J. Ivanyi, A. H. J. Kolk, W. Britten, T. Gillis and the World Health Organization for monoclonal antibodies, and C. Shepard for the $M$. leprae-infected armadillo. We also thank D. Baltimore, J. Convit, T. Godal, N. Oliver and C. Shepard for advice and discussion and S. Raines for preparing the manuscript. This research was supported by grants from the WHO/World Bank/UNDP Special Programme for Research and Training in Tropical Diseases; from the Rockefeller Foundation Program for Research in Great Neglected Diseases; from the US National Hansens Disease Center; and by USPHS grant AI2011. This paper is dedicated to the memory of $\mathrm{Dr}$ Charles Shepard.

Received 15 April; accepted 23 May 1985.

1. Bloom, B. R. \& Godal, T. Rev. Infect. Dis. 5, 765-780 (1983).

2. Hansen, G. A. Norsk Mag. Laegezitensk. 4, 1-88, I-L III (1874)

3. Ivanyi, J., Morris, J. A. \& Keen, M. in Monoclonal Antibodies Against Bacteria (eds Macario, A. J. L. \& Macario, E. C.) (Academic, New York, 1984).

4. Gillis, T. P. \& Buchanan, T. M. Infect. Immunity 37, 172 (1982)

5. Coates, A. R. M. Allen, B. W. Hewitt, J., Mitchison, D. A. \& Ivanyi, J. Lancet ii, 167 (1981).

6. Young, D. B., Fohn, M. J., Khanolkar, S. R. \& Buchanan, T. M. Clin. exp. Immun (in the press).

Engers, H. et al. Infect. Immunity 48, 603-605 (1985)

8. Young, R. A. \& Davis, R. W. Proc. natn. Acad. Sci. U.S.A. 80, 1194-1198 (1983).

9. Young, R. A. \& Davis, R. W. Science 222, 778-782 (1983)

10. Young, R. A. \& Davis, R. W. in Genetic Engineering: Principles and Techniques Vol. 7 (eds Setlow, J. \& Hollaender, A.) 29 41 (Plenum, New York, 1985).

11. Young, R. A. et al. Proc. natn. Acad. Sci. U.S.A. 82, 2583-2587 (1985).

12. Draper, P. Int. J. Lepr. 44, 95-98 (1976).

13. Clark-Curtiss, J. E., Jacobs, W. R., Docherty, M. A., Ritchie, L. R. \& Curtiss, R. J. Bact 161, 1093-1102 (1985)

14. Huynh, T., Young, R. A. \& Davis, R. W. in DNA Cloning Techniques: A Practical Approach (ed. Glover, D.) (IRL, Eynsham, in the press).

15. Bloom, B. R. \& Mehra, V. in New Approaches to Vaccine Development (eds Bell, R. \& Torrigiani, G.) 368-389 (Schwabe \& Co., Basel, 1984)

16. Davis, R. W., Botsein, D. \& Roth, J. R. Advanced Bacterial Genetics (Cold Spring Harbor Laboratory, New York, 1980).

\section{Association of rheumatoid arthritis and primary osteoarthritis with changes in the glycosylation pattern of total serum IgG}

\author{
R. B. Parekh*, R. A. Dwek*, B. J. Sutton†, \\ D. L. Fernandes*, A. Leung $\ddagger$, D. Stanworth $\ddagger$ \\ \& T. W. Rademacher*
}

Departments of *Biochemistry and †Molecular Biophysics, University of Oxford, South Parks Road, Oxford OX1 3QU, UK

$\ddagger$ Department of Immunology, Rheumatoid and Allergy Research

Unit, University of Birmingham, The Medical School, Vincent Drive, Birmingham B15 2TJ, UK

\section{T. Mizuochi§, T. Taniguchi§, K. Matsutal|, \\ F. Takeuchi\|, Y. Nagano\|, T. Miyamoto\| \\ \& A. Kobata§}

$\S$ Department of Biochemistry, Institute of Medical Science, University of Tokyo, Minato-ku, Tokyo 108, Japan

|| Department of Medicine and Physical Therapy, Faculty of Medicine, University of Tokyo, Bunkyo-ku, Tokyo 113, Japan

Rheumatoid arthritis (RA) is a widely prevalent (1-3\%) chronic systemic disease thought to have an autoimmune component ${ }^{1}$; both humoral $^{1-4}$ and cellular ${ }^{5,6}$ mechanisms have been implicated. Primary osteoarthritis (OA) is considered to be distinct from rheumatoid arthritis, and here damage is thought to be secondary to cartilage degeneration. In rheumatoid arthritis, immune complexes are present that consist exclusively of immunoglobulin ${ }^{7}$, implying that this is both the 'antibody' (rheumatoid factor [RF]) and the 'antigen' (most commonly IgG). Autoantigenic reactivity has been localized to the constant-region $\left(C_{\gamma} 2\right)$ domains of $\mathrm{IgG}^{8,9}$. There is no evidence for a polypeptide determinant but carbohydrate changes have been reported ${ }^{10}$. We have therefore conducted a study, simultaneously in Oxford and Tokyo, to compare in detail the $\mathbf{N}$-glycosylation pattern of serum IgG (Fig. 1) isolated from normal individuals and from patients with either primary osteoarthritis or rheumatoid arthritis. The results, which required an evaluation of the primary sequences of $\sim 1,400$ oligosaccharides from 46 IgG samples, indicate that: (1) IgG isolated from normal individuals, patients with RA and patients with OA contains different distributions of asparagine-linked bi-antennary complex-type oligosaccharide structures, (2) in neither disease is the IgG associated with novel oligosaccharide structures, but the observed differences are due to changes in the relative extent of galactosylation compared with normal individuals. This change results in a 'shift' in the population of IgG molecules towards those carrying complex oligosaccharides, one or both of whose arms terminate in $\mathrm{N}$ acetylglucosamine. These two arthritides may therefore be glycosylation diseases, reflecting changes in the intracellular processing, or post-secretory degradation of $\mathbf{N}$-linked oligosaccharides.

At least 30 different complex-type bi-antennary oligosaccharides are associated with human serum IgG (Fig. 2). To compare the molar proportions of each of these structures, each serum IgG sample was subjected to controlled hydrazinolysis to release intact its associated oligosaccharide moieties ${ }^{11}$. Reduction of the reducing terminal $\mathrm{N}$-acetylglucosamine residues using $\mathrm{NaB}^{3} \mathrm{H}_{4}$ was then performed to label radioactively each carbohydrate chain. Each labelled oligosaccharide mixture was subjected to exhaustive neuraminidase digestion in order to analyse the distribution of neutral structures. The resulting 'asialo' oligosaccharide mixtures were fractionated by Bio-Gel P-4 ( $\sim 400$ mesh) gel filtration chromatography, a technique that separates neutral oligosaccharides on the basis of their effective hydrodynamic volumes ${ }^{12}$ (Figs 2,3 ).

A comparison of the individual profiles obtained reveals several interesting points. First, all P-4 chromatograms of asialo mixtures from control individuals (Fig. 3) were essentially identical to one another (data not shown) and similar to those reported previously ${ }^{13}$. As any individual $\mathrm{IgG}$ molecule contains, on average, $2.8 \mathrm{~N}$-linked oligosaccharides ${ }^{14}$, many different IgG subpopulations must exist, each unique with respect to the sequence of its associated oligosaccharides. Further, the overall relative molar contribution of each of the 30 or so structures in the analysis of polyclonal IgG is remarkably constant. The occurrence of this large number of different oligosaccharides is not the result of performing the analysis on polyclonal IgG, because this same 'set' of structures is found on human myeloma proteins ${ }^{13}$ and an analogous situation exists for mouse monoclonal antibodies ${ }^{14}$. Second, the P-4 chromatograms of asialo mixtures from patients with rheumatoid arthritis are also essentially the same between patients (data not shown), but differ from control profiles (Fig. 3). Third, the asialo oligosaccharide 

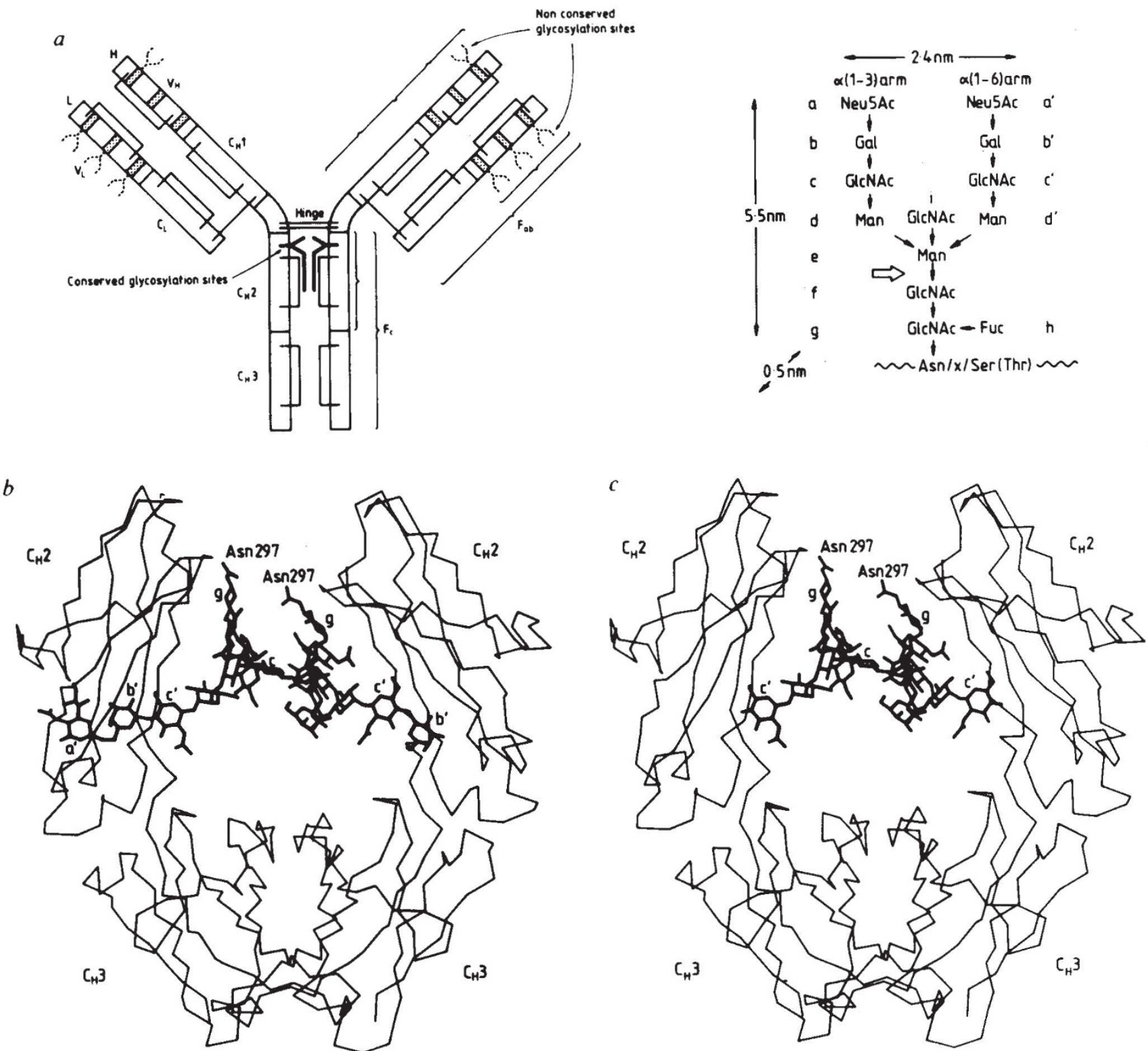

Fig. 1 a, The antibody molecule consists of two heavy $(\mathrm{H})$ and two light $(\mathrm{L})$ chains, linked by disulphide bridges (solid lines) and is divided into homologous regions of sequence $\left(\mathrm{V}_{\mathrm{H}}, \mathrm{C}_{\mathrm{H}} 1, \mathrm{C}_{\mathrm{H}} 2\right.$ and $\left.\mathrm{C}_{\mathrm{H}} 3\right)$, each of which has an intra-chain disulphide bridge. (The pattern of inter-chain disulphide bridging shown here is characteristic of human subclass IgGl.) In $V_{H}$ and $V_{L}$, the dotted segments represent the hypervariable regions of sequence that, in the three-dimensional structure, together form the antigen-binding site. The conserved asparagine-linked bi-antennary complex oligosaccharide chains are attached to Asn 297 in the $\mathrm{C}_{\mathrm{H}}{ }^{2}$ domains ${ }^{16}$. Oligosaccharide attachment sites are found in the Fab region. Their frequency and location are dependent on the presence of Asn-X-Ser sites in the hypervariable regions ${ }^{27,28}$. The relative size of an immunoglobulin domain and a fully extended $N$-linked complex oligosaccharide ${ }^{29}$ are similar. Complex-type oligosaccharides present on IgG can be subdivided into an outer-arm region $\left(a, a^{\prime}, b, b^{\prime}, c, c^{\prime}\right)$, and the core, which is composed of a trimannosyl unit (d, d', e) and a $N, N^{\prime}$-diacetylchitobiosyl unit (f, g). The 'bisect' GlcNAc (residue i) is linked $\beta(1-4)$ and the fucose (residue $\mathrm{h}$ ) is linked $\alpha(1-6)$. The arrow between residues $\mathrm{e}$ and $\mathrm{f}$ indicates the site of interaction between the two oligosaccharides in $b$ and $c$. $\boldsymbol{b}$, Refined structure at $2.8 \AA$ of rabbit Fc fragment from the crystal data of Sutton and Phillips (ref. 16 and B. J. Sutton, unpublished data). The two carbohydrate chains, each attached at Asn 297, differ in conformation and may also differ in sequence and bridge the two $\mathrm{C}_{\mathrm{H}} 2$ domains. The $\alpha(1-3)$ arm of the chain (left side) is always devoid of galactose and interacts through its $\beta(1-2)$-linked GlcNAc residue (c) with the Man $\beta(1-4)$ GlcNAc segment of the opposing (right side) oligosaccharide chain (see $a$ ). The $\alpha(1-3)$ arm of the right chain extends outwards between the domains with no apparent steric constraints on its length. A Neu5Ac unit ( $\left.a^{\prime}\right)$ is shown on one $\alpha(1-6)$ arm only (left). The electron density for this unit is weak, and experimentally, no disialylated oligosaccharide chains occur on the $\mathrm{Fc}^{14}$. The extent of oligosaccharide heterogeneity in a single crystal is identical to that found in pooled $\mathrm{Fc}$ fragments ${ }^{14,30}$, consequently the X-ray data represent the composite structure. $c$, Fc fragment containing oligosaccharides devoid of galactose and sialic acid on each of the $(\alpha 1 \rightarrow 6)$ arms. Since these residues in normal IgG are in contact with the surface of the protein (see $b$ ), their absence vacates oligosaccharide-binding sites in IgG from arthritic patients and could make the IgG 'sticky' by creating a lectin-like activitv It is not known to what extent the remaining sugar residues remain in contact with the peptide.

P-4 chromatograms of osteoarthritic (OA) patients are also characteristic of all such patients and are distinct from both the control and rheumatoid arthritic (RA) profiles (Fig. 3). Finally, the differences between the control and arthritic (both osteoarthritic and rheumatoid) P-4 profiles can be rationalized in terms of a population shift towards oligosaccharide structures of lower hydrodynamic volume. To establish the molecular basis of this shift, the asialo oligosaccharides from each patient were analysed with respect to their relative levels of different core substitutions and the degree and nature of their outer-arm substitutions (see Figs 1, 4).

For the asparagine-linked oligosaccharides of IgG, core substitutions can be readily determined by digesting the pool of oligosaccharides with a mixture of Streptococcus pneumoniae 
Table 1 Per cent oligosaccharide chains lacking galactose in serum IgG

\begin{tabular}{|c|c|c|c|c|c|c|c|c|}
\hline \multirow{2}{*}{$\begin{array}{l}\text { Individual patients } \\
\text { Oxford series }\end{array}$} & \multicolumn{2}{|c|}{ Control } & \multicolumn{2}{|c|}{ Osteoarthritis } & \multicolumn{3}{|r|}{$\begin{array}{c}\text { Duration } \\
\text { disease }(\mathrm{yr})\end{array}$} & Serology \\
\hline & Oxf1 & 26.7 & Oxf $7 f^{*}$ & 38.9 & Oxf13f & 51.5 & 25 & + \\
\hline & Oxf2 & 23.9 & Oxf $8 f^{*}$ & 36.0 & Oxf14f & 53.7 & 18 & + \\
\hline & Oxf3 & 26.2 & Oxf9f & 26.5 & Oxf15f & 41.9 & 2 & + \\
\hline & Oxf4 & 23.4 & Oxf $10 \mathrm{~m}$ & 35.2 & Oxf16f & 43.6 & 13 & - \\
\hline & Oxf5 & 16.5 & Oxf11f & 31.4 & Oxf17f & 54.9 & 3 & + \\
\hline & Oxf6 & 19.3 & Oxf12f & 33.0 & Oxf18f & 55.0 & 23 & - \\
\hline Tokyo series & Tok1f & 31.4 & Tok9f & 32.2 & Tok $16 \mathrm{~m}$ & 44.3 & 4 & + \\
\hline & Tok $2 \mathrm{~m}$ & 26.8 & Tok10f & 32.7 & Tok17f & 53.8 & 10 & + \\
\hline & Tok3m & 38.9 & Tok11f & 32.7 & Tok18f & 52.4 & 16 & + \\
\hline & Tok $4 \mathrm{~m}$ & 25.4 & Tok12f* & 47.4 & Tok19f & 48.4 & 13 & + \\
\hline & Tok5f & 23.3 & Tok13f & 43.2 & Tok $20 \mathrm{~m}$ & 43.9 & 16 & + \\
\hline & Tok6f & 19.4 & Tok14f & 33.4 & Tok21f & 47.9 & 18 & + \\
\hline & Tok $7 \mathrm{~m}$ & 28.7 & Tok15f & 35.4 & & & & \\
\hline & Tok8f & 25.7 & & & & & & \\
\hline Mixed series & & & & & $\mathrm{O} / \mathrm{T} 1 \mathrm{~m}$ & 74.5 & 18 & + \\
\hline & & & & & $\mathrm{O} / \mathrm{T} 2 \mathrm{f}$ & 56.2 & 27 & + \\
\hline & & & & & $\mathrm{O} / \mathrm{T} 3 \mathrm{~m}$ & 55.6 & $>15$ & + \\
\hline & & & & & $\mathrm{O} / \mathrm{T} 4 \mathrm{f}$ & 51.8 & 15 & + \\
\hline & & & & & $\mathrm{O} / \mathrm{T} 5 \mathrm{~m}$ & 44.3 & 15 & + \\
\hline & & & & & $\mathrm{O} / \mathrm{T} 6 \mathrm{~m}$ & 38.7 & $>10$ & + \\
\hline Mean \pm s.d. & Oxf & $22.7 \pm 4.0$ & & $33.5 \pm 4.3$ & & $50.1 \pm 5.9$ & & \\
\hline & Tok & $27.5 \pm 5.8$ & & $36.7 \pm 6.1$ & & $51.0 \pm 9.1$ & & \\
\hline Pooled control serum & Bern-1† & 24.0 & & - & & - & & \\
\hline
\end{tabular}

Rheumatoid arthritis

Non-galactosylated oligosaccharides were isolated as follows. Asialo oligosaccharides $\left(1 \times 10^{7}\right.$ c.p.m. $)$ from the IgG of each individual were applied to an RCA-120 agarose column (Miles-Yeda, Lot no. AR26) of dimensions $0.6 \times 20 \mathrm{~cm}$. The column was developed in $5 \mathrm{mM}$ sodium acetate ( $p \mathrm{H}$ 5.6). Non-galactosylated structures eluted in the void while digalactosylated and monogalactosylated structures eluted later and at unique volumes (data not shown). The number of galactose residues in each peak was confirmed by following the change in hydrodynamic volume after digestion with jack bean $\beta-N$-acetyl hexosaminidase $\left(14 \mu \mathrm{M}\right.$ substrate, $150 \mathrm{U} \mathrm{ml}^{-1}$ of enzyme in $0.1 \mathrm{M}$ citrate phosphate, $\left.p \mathrm{H} 4.5\right)$. For the Oxford series, the differences in the means were significant, with $P=0.002$ (C vs OA) and $P<0.001$ (C vs RA) and $P=0.002$ (OA vs RA). For the Tokyo series (including data from Tok and $\mathrm{O} / \mathrm{T}$ patients), the significance was $P=0.006$ (C vs OA), $P<0.001(\mathrm{C}$ vs RA) and $P=0.0008(\mathrm{OA}$ vs RA). Any difference in the means between the two series was not considered statistically significant and no correlation was found between the extent of galactosylation and age and sex. The ratios of digalactosylated to monogalactosylated structures obtained as described in the text were as follows: C, $0.89 \pm 0.09 ; \mathrm{OA}, 0.75 \pm 0.15 ; \mathrm{RA}, 0.63 \pm 0.12$. The statistical significance of these is $P=0.07$ (C vs OA), $P=0.0003$ (C vs RA), $P>0.1$ (OA vs RA). Statistical analysis was performed using a non-parametric combined-order statistic test (Wilcoxon-Mann-Whitney test ${ }^{25}$ ). Probabilities are quoted for a two-tailed test with a null hypothesis $H_{0}: \mu_{1}=\mu_{2}$ tested against an alternative hypothesis $H_{1}: \mu_{1} \neq \mu_{2}$. The mixed series refers to serum samples from British individuals, where the IgG was purified in England and sugar analysis performed in Tokyo. Blood samples in the Oxford series were obtained from patients at St John's Highfield Hospital, Droitwich, UK, and the Queen Elizabeth Medical Centre, Birmingham, UK. Patients Oxf13 to Oxf18, Tok16 to Tok 21 and O/T1 to O/T6 had active disease and all fulfilled the American Rheumatism Association criteria for definite or classical rheumatoid arthritis ${ }^{26}$. The Oxf patients range in age was 50-75 yr (mean, RA $64 \pm 8$ s.d.; OA, $68 \pm 9$ s.d.), and the Tok patients 41-75 yr (mean, RA $57 \pm 14$ s.d.; OA, $58 \pm 9$ s.d.). Control serum in the Oxf series was obtained from random blood bank donors. The Tok series control serum was from donors, age range $22-47 \mathrm{yr}$ (mean $38 \pm 9$ s.d.). The analysis was performed double-blind, with clinical histories obtained after completion of oligosaccharide analysis.

* Patients $\mathrm{Oxf7}$ and $\mathrm{Oxf8}$ had long-standing osteoarthritis and very recently have been showing signs of an inflammatory component (6 months and 24 months respectively). The patient Tok 12 (aged $74 \mathrm{yr}$ ) was originally diagnosed as osteoarthritic but now also has Sjögren's syndrome.

† Bern-1 refers to IgG from the pooled serum of several thousand individuals and was given by Dr U. Nydegger of the Blood Transfusion Centre of the Swiss Red Cross, Bern, Switzerland.

$\beta$-galactosidase and $\beta$ - $N$-acetylhexosaminidase ${ }^{13}$. The resulting digestion products are diagnostic for each of the four cores and differ sufficiently in hydrodynamic volume to be resolved on a P-4 column. The results (Fig. 4) indicate clearly that there is no systematic correlation between disease state and the incidence of any particular type of core structure (that is, no apparent changes in the levels of the enzymes GnT III (ref. 15) and $\alpha(1 \rightarrow 6)$ fucosyltransferase).

The outer-arm structures can be characterized with respect to the incidence, linkage and location of galactose, $N$ acetylglucosamine and $N$-acetylneuraminic acid. The asialo oligosaccharide mixtures were therefore subjected to Ricinus communis lectin-agarose affinity chromatography to separate galactosylated and non-galactosylated structures. Table 1 shows that in control IgG, $\sim 75 \%$ of all oligosaccharide chains contain at least one galactose residue. In $\mathrm{IgG}$ isolated from rheumatoid and osteoarthritic patients, only $\sim 50 \%(P=0.001)$ and $\sim 65 \%$ $(P=0.002)$, respectively, of the chains contained galactose. The ratio in each individual case of digalactosyl to monogalactosyl structures was determined either by chromatography of the galactosylated oligosaccharides on $R$. communis lectin-agarose, or enzymatically. In the latter, digestion with jack bean $\beta-N$ - acetylhexosaminidase, followed by P-4 gel permeation chromatography, results in the resolution of fragments diagnostic of the digalactosylated and monogalactosylated structures. The ratios of the digalactosyl to monogalactosyl structures obtained by both methods were consistent and indicated respective decreases of $30 \%(P=0.0003)$ and $15 \%(P=0.07)$ in the rheumatoid and osteoarthritic asialo oligosaccharide mixtures.

To determine whether the decreased number of chains containing galactose was secondary to a decrease in outer-arm $\beta(1-2)$ linked $N$-acetylglucosamine residues, the asialo oligosaccharide structures from each individual were digested with jack bean $\beta$-galactosidase and the resulting degalactosylated oligosaccharides subjected to P-4 chromatography. In all three groups essentially identical profiles were found, implying no deficiency in outer-arm $\beta(1-2)$-linked $N$-acetylglucosamine residues (GlcNAc 5 and 5', Fig. 2). There can, therefore, be no difference between individuals, regardless of their disease state, with respect to the extent of $\mathrm{N}$-acetylglucosaminylation (that is, no apparent change in the levels of enzymes GnT I and GnT II (ref. 15)).

As the negatively charged $\mathrm{N}$-acetylneuraminic acid residues confer mobility in an electric field, an aliquot of the labelled 
Fig. 2 Primary sequences of the $N$-linked oligosaccharides associated with human IgG. The hydrodynamic volume (as measured in glucose units) of each structure (or of its neutral derivative in the case of those sialylated) is indicated (refs 12, 13 and R.B.P. et al., unpublished data), and was determined by comparison with $\alpha(1-6)$-linked glucose oligomer standards.

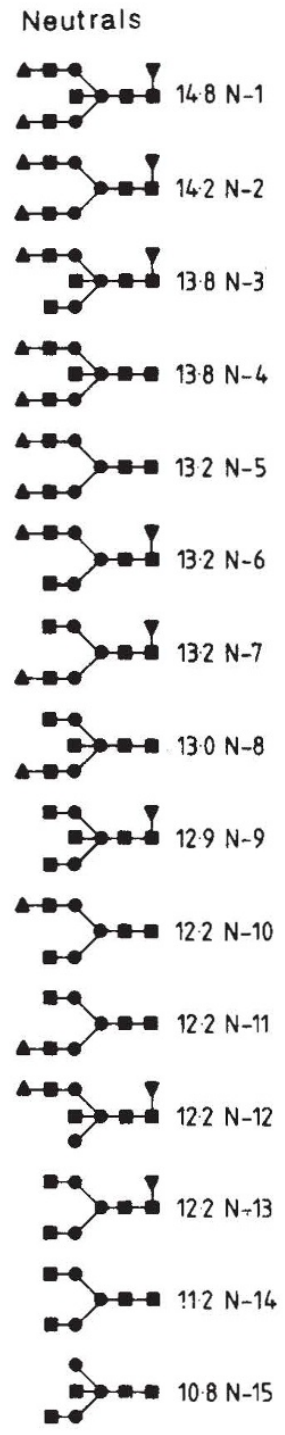

\section{Monosialylated}
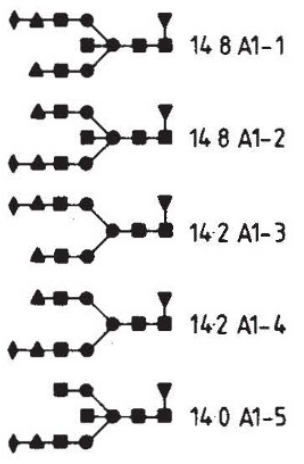

rato

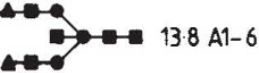

\section{$\rightarrow-$}

$\Rightarrow \rightarrow 13.8$ A1-7

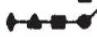

$\rightarrow-2,7$

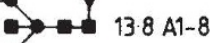

$-$

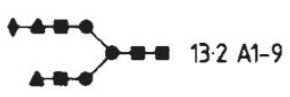

$\rightarrow-a$

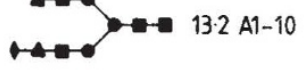

$\rightarrow \rightarrow-1$

$132.21-11$
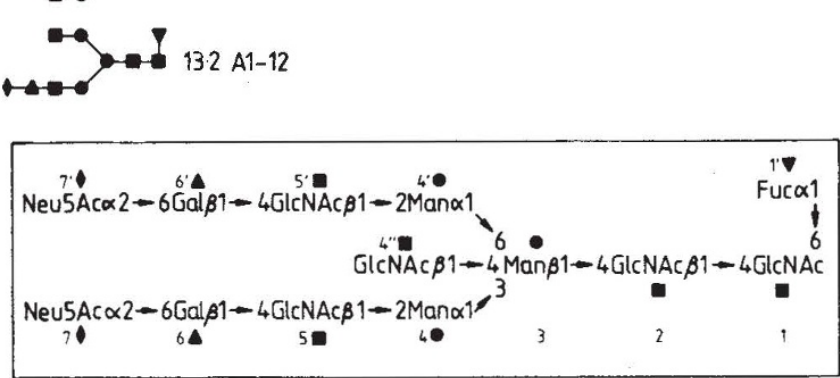

oligosaccharide pool (before neuraminidase digestion) was subjected to high-voltage paper electrophoresis. The oligosaccharides were completely separated into neutral, monosialylated and disialylated structures. The occurrence of these structures is represented in Fig. 4 and the structures present in the three peaks are detailed in Fig. 2. Within each study the osteoarthritis and rheumatoid IgGs show a slight decrease in the number of chains terminating with one or two $\mathrm{N}$-acetylneuraminic acid residues, consistent with their decrease in galactosylation.

The results show that osteoarthritis, and particularly rheumatoid arthritis, are associated with marked changes in the level of outer-arm galactosylation of the complex $\mathrm{N}$-linked oligosaccharides of serum IgG $(P=0.002 \mathrm{OA}$ versus control (C), $P=0.001 \mathrm{RA}$ versus $\mathrm{C}$ ) and these also distinguish the disease states $(P=0.002$ OA versus RA). Importantly, no novel oligosaccharides were found on IgG from either of the arthritides (data not shown).

A possible consequence of this change in galactosylation is suggested by recent $\mathrm{X}$-ray crystallographic studies on rabbit $\mathrm{Fc}$, which have helped to define in molecular terms the manner in which the opposing oligosaccharides interact with each other and with the peptide ${ }^{16}$. In particular, the oligosaccharide chains appear to have different primary sequences (and hence many IgG molecules are structurally asymmetrical) and conformations (Fig. 1b). The $\alpha(1-6)$ arms interact with the protein surface, the major contacts being through their Neu5Aca (2-6) Gal $\beta(1$ 4)GlcNAc segment. The rigid ${ }^{17} \alpha(1-3)$ arm of at least one of the paired oligosaccharides is always devoid of galactose, thereby exposing its outer-arm $\beta(1 \rightarrow 2)$ linked $N$ acetylglucosamine residue, which then interacts directly with the Man $\beta$ (1-4)GlcNAc segment of the opposing carbohydrate chain. The $\alpha(1-3)$ arm of the latter oligosaccharide extends outwards between the domains with no apparent steric constraints on its length (Fig. $1 b$ ).

Given this minimum restriction on pairing of oligosaccharides in $\mathrm{Fc}$, a probability analysis reveals that the above changes in galactosylation would lead to a marked elevation in the incidence of Fc molecules that totally lack galactose $(\sim 300 \%$ in rheumatoid arthritis and $\sim 90 \%$ in osteoarthritis, that is, from $10 \%$ in normal serum to $19 \%$ in osteoarthritis and $40 \%$ in rheumatoid arthritis). Thus, the hierarchical set of changes, beginning with an altered level of galactosylation and proceeding via a change in the relative populations of a constant set of oligosaccharide structures, leads through the phenomenon of pairing in the Fc, to dramatic changes in the incidence of individual Fc subpopulations. Such a change in IgG could result in the formation and/or persistence of immunoglobulin complexes by any one of several possible mechanisms that may or may not involve a true autoimmune response. First, oligosaccharides now terminating in $\mathrm{N}$-acetylglucosamine could expose previously masked protein determinants or create new proteinoligosaccharide determinants that may be immunogenic. Second, an increase in the level of certain IgG subpopulations could lead to the exposure of certain Fc determinants at much higher concentrations than before. This could elicit a new immune response or raise a pre-existing low-level (subclinical) 
Fig. 3 Representative Bio-Gel P-4 ( 400 mesh) gel permeation chromatograms of the asialo oligosaccharides of total serum IgG: $a$, control; $b$, rheumatoid arthritis; $c$, osteoarthritis.

Methods. $\mathrm{lgG}$ from the serum of each of 42 individuals was isolated by precipitation at $4{ }^{\circ} \mathrm{C}$ with ammonium sulphate $(33 \%)$ and $\mathrm{DE}-52$ ionexchange chromatography $\left(4^{\circ} \mathrm{C}\right)$ in $0.01 \mathrm{M} \mathrm{NaPO}_{4} p \mathrm{H} 7.2$. In the Tokyo series, oligosaccharides of each purified $\mathrm{IgG}$ were released by hydrazinolysis and analysed by Bio-Gel P.4 column chromatography (after sialidase treatment) as reported previously ${ }^{13}$. In the Oxford series, each purified IgG $(5 \mathrm{mg})$ was dialysed exhaustively against distilled water $\left(4^{\circ} \mathrm{C}\right)$ and cryogenically dried over activated charcoal at $-196^{\circ} \mathrm{C}\left(<10^{-6}\right.$ bar $)$. Protein samples were suspended in freshly distilled anhydrous hydrazine for $8 \mathrm{~h}$ at $100{ }^{\circ} \mathrm{C}$ under an anhydrous argon atmosphere. The hydrazine was removed by repeated $(5 \times)$ flash-evaporation from anhydrous toluene. The hydrazinolysates were $N$-acetylated by addition of an excess of acetic anhydride in saturated $\mathrm{NaHCO} 3$ at $4^{\circ} \mathrm{C}$. After passage through a column of Dowex AG $50 \times 12\left(\mathrm{H}^{+}\right.$form $)$, the samples were evaporated to dryness $\left(27^{\circ} \mathrm{C}\right)$, re-dissolved in water and applied to Whatman $3 \mathrm{MM}$ chromatography paper. Descending paper chromatography $\left(27^{\circ} \mathrm{C}\right)$ was subsequently performed using $n$-butanol/ethanol/water $(4: 1: 1 \mathrm{v} / \mathrm{v}$ ) (solvent I). After $48 \mathrm{~h}$ the first $5 \mathrm{~cm}$ measured from the origin was eluted with $\mathrm{H}_{2} \mathrm{O}$. The oligosaccharides so isolated were flash-evaporated to dryness $\left(27^{\circ} \mathrm{C}\right)$ and reduced with a

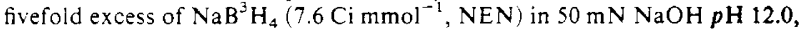
$30^{\circ} \mathrm{C}$ for $4 \mathrm{~h}$. An equivalent volume of $1 \mathrm{M} \mathrm{NaBH}_{4}$ in $50 \mathrm{mM} \mathrm{NaOH} p \mathrm{H}$ 12.0 was then added and incubation continued for $2 \mathrm{~h}$. The mixture was then acidified ( $p \mathrm{H} 5-6$ ) with $1 \mathrm{M}$ acetic acid and passed through a Dowex AG $50 \times 12\left(\mathrm{H}^{+}\right)$column, evaporated to dryness $\left(27^{\circ} \mathrm{C}\right)$ and flash-evaporated $\left(27^{\circ} \mathrm{C}\right)$ from methanol $(\times 5)$. The samples were then applied to Whatman $3 \mathrm{MM}$ paper and subjected to descending paper chromatography for 2 days in solvent $\mathrm{I}$. Radiochromatogram scanning was performed with a Berthold radiochromatogram scanner $\mathrm{LB} 280$. The radioactivity at the origin was subsequently eluted with water. An aliquot of reduced $\left[{ }^{3} \mathrm{H}\right]$-labelled oligosaccharides so isolated was subjected to exhaustive neuraminidase digestion (Arthrobacter ureafaciens, Nakarai Chemical Co., Kyoto, Japan); radioactive sugar $\left(1 \times 10^{7}\right.$ c.p.m. $)$ in $50 \mu \mathrm{l}$ of $0.1 \mathrm{M}$ sodium acetate $p \mathrm{H} 5.0$ containing $0.1 \mathrm{U}$ of enzyme. Incubation was performed at $37^{\circ} \mathrm{C}$ for $18 \mathrm{~h}$ under a toluene atmosphere. The samples were then subjected to high-voltage paper electrophoresis at $80 \mathrm{~V} \mathrm{~cm}^{-1}$ in pyridine/acetic acid/water $(3: 1: 387 \mathrm{v} / \mathrm{v}, p \mathrm{H} 5.4)$. All radioactivity remained at the origin (data not shown), confirming the complete cleavage of sialic acid. The samples were recovered from paper by elution with water, desalted using a tandem column of Dowex $\mathrm{AG} 50 \times 12\left(\mathrm{H}^{+}\right)$and $\mathrm{AG} 3 \times 4 \mathrm{~A}\left(\mathrm{OH}^{-}\right)$in water, evaporated to dryness, resuspended in $175 \mu \mathrm{l}$ of a $20 \mathrm{mg} \mathrm{m}^{-1}$ partial dextran acid hydrolysate and applied to a Bio-Gel P.4 ( $\sim 400$ mesh) gel permeation chromatography column $(1.5 \mathrm{~cm} \times 200 \mathrm{~cm})$. The column was maintained at $55^{\circ} \mathrm{C}$ and water $\left(200 \mu \mathrm{l} \mathrm{min}{ }^{-1}\right)$ was used as the eluent. The eluent was monitored for radioactivity using a Berthold HPLC radioactivity monitor (model LB503) and for refractive index using a Perkin-Elmer model LC25 refractometer. Analog signals from the monitors were digitized using Nelson Analytical $A D C$ interfaces. The digital values were collected and analysed using Hewlett Packard $9836 \mathrm{C}$ computers. The figure shows radioactivity (vertical axis) plotted against retention time after removal of stochastic noise using Fourier transform techniques. The numerical superscripts refer to the elution position of glucose oligomers in glucose units as detected simultaneously by the refractive index monitor (data not shown). $V_{0}$ is the void position. Sample elution positions (in glucose units) were calculated by cubic spline interpolation between the internal standard glucose oligomer positions. The insets are of resolution-enhanced profiles drawn with the retention time axis unchanged and the radioactivity axis reduced by 0.5 . Resolution-enhancement was achieved by lineshape transformation in the Fourier domain.

response to a pathological one. Third, the oligosaccharidebinding sites in the $\mathrm{C}_{\nu} 2$ domain, which are normally occupied by Neu 5 Ac $\alpha(2-6)$ Gal segments of the $(\alpha 1 \rightarrow 6)$ arm, are now vacant and could effectively make the IgG 'sticky' by creating a lectin-like activity (see Fig. 1c). This could result in complex formation or auto-aggregation without an actual autoimmune response. Such a mechanism is implicit in some prevous studies $^{18,19}$ and in the occurrence of rheumatoid factor in apparently normal individuals. In particular, it would readily explain the weak affinity of binding between Fab and Fc in IgG complexes in rheumatoid serum ${ }^{8,20}$ and the unusual properties of many rheumatoid factors, for example, the monovalency of their interaction with $\mathrm{IgG}^{7,8}$ and their selective cross-reactivity with IgG from other species ${ }^{8,21,22}$. None of the above mechanisms requires the oligosaccharide itself to be immunogenic and all are therefore consistent with the lack of any novel oligosaccharides on the IgG of rheumatoid arthritis patients.

Primary osteoarthritis is also associated with an altered glycosylation pattern of serum IgG, yet this disease is generally considered clinically distinct from rheumatoid arthritis and is not associated with pathological levels of immunoglobulin com-

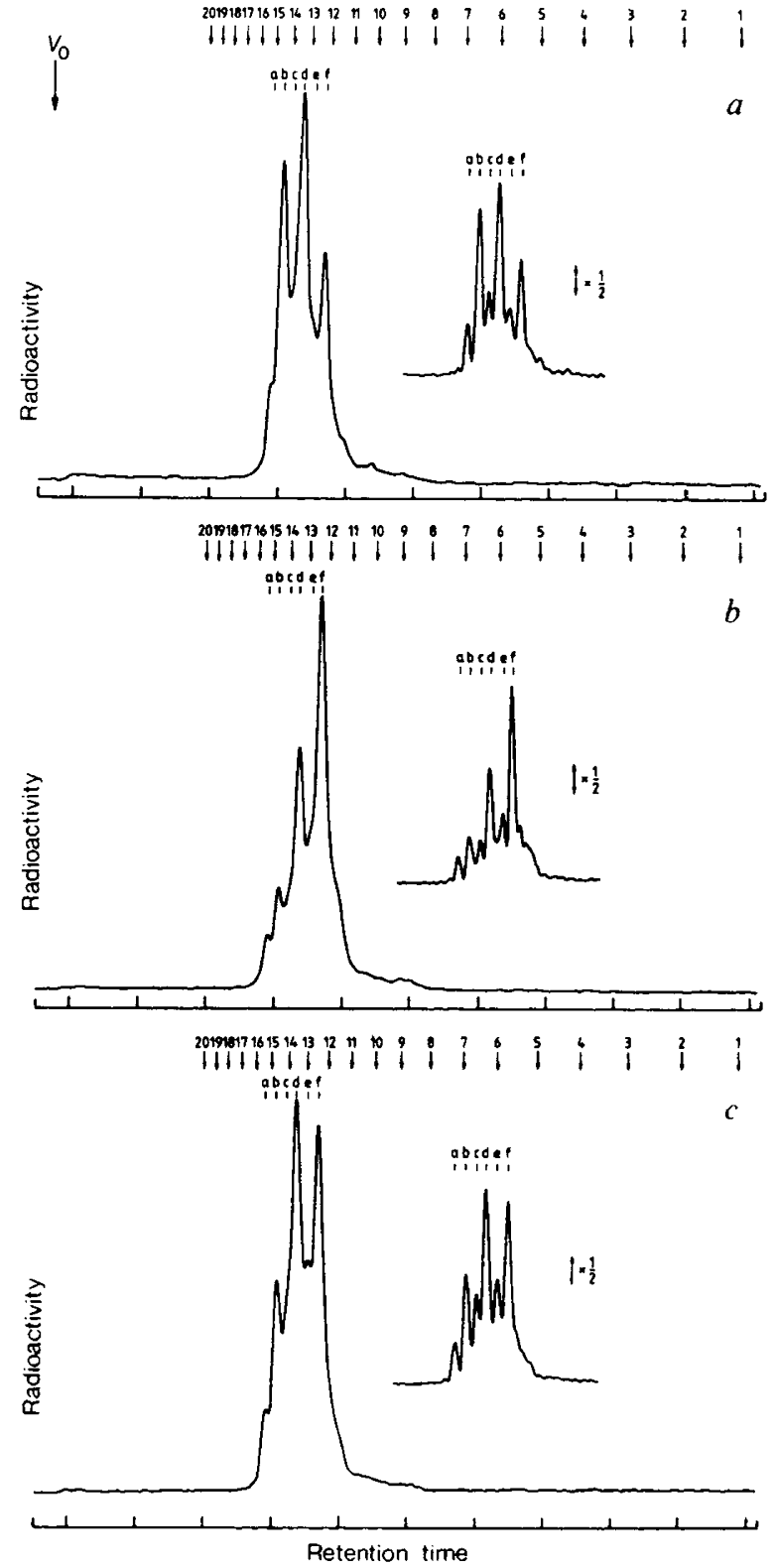

plexes in the serum. Possibly the much smaller decrease in galactosylation of the IgG in osteoarthritis ensures that the level and size of any immunoglobulin complexes formed is too low to lead to a persistent inflammatory component, although subclinical levels of such complexes may exist.

As the glycosylation of IgG is altered, it is probable that the glycosylation of other glycoproteins of B lymphocytes (for example; cell-surface class I and class II major histocompatibility complex (MHC) antigens) and perhaps other cellular compartments is also affected. Susceptibility to many autoimmune diseases and some infections (for example, leprosy) correlates with a particular allelic form of one or more genes from one of the three HLA classes ${ }^{23}$. In rheumatoid arthritis susceptibility is strongly correlated with the presence of the HLA-DRw4 allele $^{23,24}$. The correlation between decreased galactosylation and occurrence of rheumatoid arthritis raises the possibility that altered glycosylation of certain MHC-region products may be one of the means by which this genomic region can influence disease susceptibility.

We thank Professor R. R. Porter and Dr G. E. Paget for their interest and encouragement throughout this work. The Oxford 


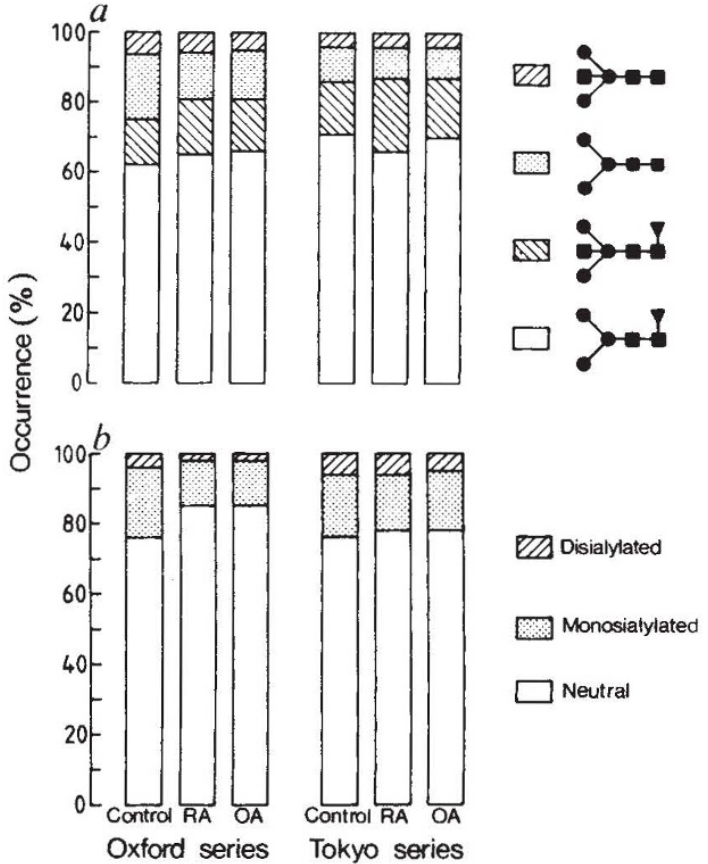

Fig. 4 a, Relative occurrence of the four core structures. An aliquot (3-5x $10^{3}$ c.p.m.) of the unfractionated asialo oligosaccharides was digested with a mixture of $S$. pneumoniae $\beta$-galactosidase $(2 \mathrm{mU})$ and $\beta$ - $N$-acetylhexosaminidase $(4 \mathrm{mU})$ in $25 \mu \mathrm{l}$ of $0.1 \mathrm{M}$ citrate phosphate $p \mathrm{H} 6.0$. The digestion was performed at $37^{\circ} \mathrm{C}$ for $18 \mathrm{~h}$ under a toluene atmosphere and terminated by heating to $100^{\circ} \mathrm{C}$ for $2 \mathrm{~min}$. After desalting [Dowex AG $50 \times 12$ $\left.\left(\mathrm{H}^{+}\right), \mathrm{AG} 3 \times 4 \mathrm{~A}\left(\mathrm{OH}^{-}\right)\right]$, the digestion products were separated on a Bio-Gel P-4 ( 400 mesh) column. Enzymes were purified by a modification of the method of Glagow et al. ${ }^{31} S$. pneumoniae $\beta$-galactosidase removes all galactose residues from the asialo oligosaccharides of $\mathrm{IgG}$, irrespective of their core structures (data not shown). S. pneumoniae $\beta-N$-acetylhexosaminidase digests the resulting oligosaccharides in a manner dependent on the presence of the (bisecting) GlcNAc $\beta 1 \rightarrow 4$ residue $^{32}$. Specifically, only one $N$ acetylglucosamine residue (GlcNAc 5 in Fig. 2) is released from the agalactosyl structure GicNAc $\beta 1 \rightarrow 2 \operatorname{Man} \alpha 1 \rightarrow 6$ (GlcNAc $\beta 1 \rightarrow 2$ Man $\alpha 1 \rightarrow 3$ ) $($ GlcNAc $\beta 1 \rightarrow 4)$ Man $\beta 1 \rightarrow 4$ GlcNAc $\beta 1 \rightarrow 4( \pm$ Fuc $\alpha 1 \rightarrow 6)$ GlcNAc, which is converted to GlcNAc $\beta 1 \rightarrow 2 \operatorname{Man} \alpha 1 \rightarrow 6(\operatorname{Man} \alpha 1 \rightarrow 3)($ GlcNAc $\beta 1 \rightarrow 4)$ Man $\beta 1 \rightarrow 4$ GlcNAc $\beta 1 \rightarrow 4( \pm$ Fuc $\alpha 1 \rightarrow 6$ ) GlcNAc. However, two $N$ acetylglucosamine residues are released from GlcNAc $\beta 1 \rightarrow 2$ Man $\alpha 1 \rightarrow 6$ $($ GlcNAc $\beta 1 \rightarrow 2$ Man $\alpha 1 \rightarrow 3)$ Man $\beta 1 \rightarrow 4$ GlcNAc $\beta 1 \rightarrow 4( \pm$ Fuc $\alpha 1 \rightarrow 6$ ) GlcNAc, which is converted to Man $\alpha 1 \rightarrow 6$ (Man $\alpha 1 \rightarrow 3$ ) Man $\beta 1 \rightarrow 4$ GlcNAc $\beta 1 \rightarrow 4$ ( \pm Fuc $\alpha 1 \rightarrow 6$ ) GlcNAc. The four cores have the following structures: $(+B-F), \operatorname{Man} \alpha 1 \rightarrow 6(\operatorname{Man} \alpha 1 \rightarrow 3)(\operatorname{GlcNAc} \beta 1 \rightarrow 4) \operatorname{Man} \beta 1 \rightarrow$ $4 \mathrm{GlcNAc} \beta 1 \rightarrow 4 \mathrm{GlcNAc}$; 缽, $(-\mathrm{B}-\mathrm{F}), \operatorname{Man} \alpha 1 \rightarrow 6(\operatorname{Man} \alpha 1 \rightarrow 3) \operatorname{Man} \beta 1 \rightarrow$ 4GlcNAc $\beta 1 \rightarrow 4 \mathrm{GlcNac}$; $\quad(+\mathrm{B}+\mathrm{F}), \quad \operatorname{Man} \alpha 1 \rightarrow 6(\operatorname{Man} \alpha 1 \rightarrow 3)$ $($ GlcNAc $\beta 1 \rightarrow 4) \operatorname{Man} \beta 1 \rightarrow 4$ GlcNAc $\beta 1 \rightarrow 4$ (Fuc $\alpha 1 \rightarrow 6)$ GlcNAc; $\square,(-B+$ F), $\operatorname{Man} \alpha 1 \rightarrow 6(\operatorname{Man} \alpha 1 \rightarrow 3) \operatorname{Man} \beta 1 \rightarrow 4$ GlcNAc $\beta 1 \rightarrow 4$ (Fuc $\alpha 1 \rightarrow 6)$ GlcNAc. The percentage of each core as determined in the Oxford series was: $+\mathrm{B}-\mathrm{F}$ : C, $6.6 \pm 2.5 ; \mathrm{OA}, 5.1 \pm 2.2 ; \mathrm{RA}, 6.0 \pm 2.2 ;-\mathrm{B}-\mathrm{F}: \mathrm{C}, 18.5 \pm 6.5 ; \mathrm{OA}, 13.0 \pm 4.3$; RA, $14.3 \pm 3.1 ;+B+F: C, 13.2 \pm 3.1 ; O A, 15.1 \pm 3.9 ; R A, 15.8 \pm 5.0 ;-B+F$ : C, $61.8 \pm 10.6 ; \mathrm{OA}, 66.8 \pm 7.2 ; \mathrm{RA}, 63.9 \pm 6.0$. The values determined in the Tokyo series were: $+\mathrm{B}-\mathrm{F}$ : C, $3.8 \pm 2.7 ; \mathrm{OA}, 3.7 \pm 0.8 ; \mathrm{RA}, 4.6 \pm 1.4 ;-\mathrm{B}-\mathrm{F}$ : C, $8.8 \pm 2.9 ; \mathrm{OA}, 9.7 \pm 2.4 ; \mathrm{RA}, 8.8 \pm 2.1 ;+\mathrm{B}+\mathrm{F}$ : C, $14.6 \pm 1.9, \mathrm{OA}, 16.6 \pm 4.0$; RA, 20.9 $\pm 5.7 ;-B+F$ : C, $72.8 \pm 3.3 ;$ OA, $70.1 \pm 5.1$, RA, $65.7 \pm 6.7$. There is no statistical significance $(P>0.05)$ in the different incidence of any core in the three groups. $b$, Relative occurrence of oligosaccharide chains containing terminal $\alpha(2-6)$-linked $N$-acetylneuraminic acid. An aliquot $(5 \times$ $10^{6}$ c.p.m.) of ${ }^{3} \mathrm{H}$-labelled oligosaccharides was subjected to high-voltage paper electrophoresis $\left(80 \mathrm{~V} \mathrm{~cm}^{-1}\right)$ in pyridine/acetic acid/water $(3: 1: 387 \mathrm{v} / \mathrm{v})$ pH 5.4 (Camag HVE cell 61000 ). After scanning with a Berthold LB280 radiochromatogram scanner, the regions N (neutral), A-1 (first acidic) and A-2 (second acidic) were eluted and the radioactivity in each determined, allowing the ratios in each sample to be calculated. To confirm that all structures present in the A-1 and A-2 positions contained only one and two sialic acid residues respectively, an aliquot of the eluted A-1 and A-2 oligosaccharide fractions was applied to a QAE-A25 Sephadex column $(6 \mathrm{~mm} \times 10 \mathrm{~cm})$. Samples were applied in $2 \mathrm{mM}$ ammonium acetate (pH 5.3) and the column developed with a $2-350 \mathrm{mM}$ linear gradient of ammonium acetate. Both the A-1 and A-2 fractions from the paper electrophoresis gave single elution peaks corresponding to the standard elution positions of monosialylated and disialylated oligosaccharides, respectively. The percentage of each as determined in the Oxford series was: $\mathrm{N}$ : C, $75.7 \pm 5.0 ; \mathrm{OA}, 84.7 \pm 1.8$; RA, $85.2 \pm 1.1$; A-1: C, $20.5 \pm 5.0 ; \mathrm{OA}, 13.7 \pm 1.5$; RA, $12.6 \pm 1$; A-2: C, $3.8 \pm 1.6 ; \mathrm{OA}, 1.7 \pm 0.7 ; \mathrm{RA}, 2.2 \pm 0.6$. The values determined in the Tokyo series were: $\mathrm{N}$ : C, 76.1 $11.1 ; \mathrm{OA}, 78.6 \pm 2.1 ; \mathrm{RA}$ $78.4 \pm 4.4 ; \mathrm{A}-1: \mathrm{C}, 17.8 \pm 1.7 ; \mathrm{OA}, 16.5 \pm 1.8 ; \mathrm{RA}, 15.2 \pm 3.2 ; \mathrm{A}-2: \mathrm{C}, 6.1 \pm 1.5$ OA, $5.0 \pm 0.9$ ); RA, $6.5 \pm 1.5$.
Oligosaccharide Group is supported by the Monsanto Company. R.A.D., T.W.R. and B.J.S. are members of the Oxford Enzyme Group. The Tokyo Group is supported by research grants for Scientific Research, from the Ministry of Education, Science and Culture of Japan, and by a research grant from the Yamanouchi Foundation for Research on Metabolic Disorders.

Received 23 January; accepted 30 May 1985.

1. Kunkel, H. G. \& Tan, E. M. Adv. Immun. 4, 351-395 (1964).

2. Pope, R. M., Mannik, M., Gilliland, B. C. \& Teller, D. C. Arthritis Rheum. 18, 97-106 (1975).

3. Stuart, J. M., Townes, A. S. \& Kang, A. H. A. Rev. Immun. 2, 199-218 (1984).

4. Shakib, F. \& Stanworth, D. R. Ann. rheum. Dis. 37, 12-17 (1978)

5. Solinger, A. M:, Bhatnagar, R. \& Stobo, J. D. Proc. natn. Acad. Sci. U.S.A. 78, 3877-3881 (1981).

6. Klareskog, L., Forsum, U., Scheynius, A., Kabelitz, D. \& Wigzell, H. Proc natn. Acad. Sci. U.S.A. 79, 3632-3636 (1982).

7. Winchester, R. J., Kunkel, H. G. \& Agnello, V. J. exp. Med. 134, 2865 (1971).

8. Nardella, F. A., Teller, D. C. \& Mannik, M. J. exp. Med. 154, 112-125 (1981).

9. Henney, C. S. \& Stanworth, D. R. Nature 201, 511-512 (1964).

10. Mullinax, F., Hymes, A. J. \& Mullinax, G. L. Arthritis Rheum. 19, 813 (1976).

11. Takasaki, S., Mizuochi, T. \& Kobata, A. Meth. Enzym. 83, 263-268 (1982).

12. Yamashita, K., Mizuochi, T. \& Kobata, A. Meth. Enzym. 83, 105-126 (1982)

13. Mizuochi, T., Taniguchi, T., Shimizu, A. \& Kobata, A. J. Immun. 129, 2016-2020 (1982)

14. Rademacher, T. W. \& Dwek, R. A. Prog. Immun. 5, 95-112 (1983).

15. Yamashita, K., Tachibana, Y., Ohkura, T. \& Kobata, A. J. biol. Chem. 260, 3963-3969 (1985). 16. Sutton, B. J. \& Phillips, D. C. Biochem. Soc. Trans. 11, 130-132 (1982).

17. Homans, S. W., Dwek, R. A., Fernandes, D. L. \& Rademacher, T. W. FEBS Lett. 164, 231-235 (1983)

18. Heimer, R., Fenton, M. R. \& Abruzzo, L. J. Immunochemistry 8, 603-611 (1971).

19. Hymes, A. J., Mullinax, G. L. \& Mullinax, F. J. biol. Chem. 254, 3148-3151 (1979).

20. Normansell, D. E. Immunochemistry 8, 593-602 (1971).

21. Normansell, D. E. \& Stanworth, D. R. Immunology 15, 549-560 (1968).

22. Normansell, D. E. \& Stanworth, D. R. Immunology 10, 527-533 (1966).

23. Panayi, G. S. in Immunogenetics (eds Panayi, G. S. \& David, C. S.) Ch. 6 (Butterworths, London, 1984).

24. McMichael, A. J., Sasazuki, T., McDevitt, H. O. \& Payne, R. O. Arthritis Rheum. 20, 1037-1042 (1977)

25. Lloyd, E. Handbook of Application Mathematics Vol. 6, Pt B (Wiley, New York, 1984)

26. Primer on the Rheumatic Diseases 7th edn, Appendix 1 (ed. Rodman, G. P.) 137-140 (Arthritis Foundation, New York, 1973).

27. Sox, H. C. Jr. \& Hood, L. Proc natn. Acad. Sci. U.S.A. 66, 975-982 (1970).

28. Spiegelberg, H. L., Abel, A. C., Fishkin, B. G. \& Grey, H. M. Biochemistry 9, 4217-4223 (1970).

29. Montreuil, J. Biochem. Soc. Trans. 11, 134-136 (1982).

30. Rademacher, T. W. et al. Biochem. Soc. Trans. 11, 132-134 (1982)

31. Glasgow, L. R., Paulson, J. C. \& Hill, R. L. J. biol Chem. 252, 8615-8623 (1977)

32. Yamashita, K., Ohkura, T., Yoshima, H. \& Kobata, A. Biochem. biophys. Res. Commun. 100, 226-232 (1981).

\section{SV40 enhancer and large-T antigen are instrumental in development of choroid plexus tumours in transgenic mice}

\author{
Richard D. Palmiter*, Howard Y. Chen $\dagger$, \\ Albee Messing $\ddagger$ \& Ralph L. Brinster $\dagger$
}

* Howard Hughes Medical Institute, Department of Biochemistry, University of Washington, Seattle, Washington 98195 , USA $\dagger$ Laboratory of Reproductive Physiology, School of Veterinary Medicine and $\ddagger$ Division of Neuropathology, School of Medicine, University of Pennsylvania, Philadelphia, Pennsylvania 19104, USA

We have shown recently that choroid plexus tumours frequently develop in transgenic mice which have developed from fertilized eggs injected with DNA molecules containing both simian virus 40 (SV40) early-region genes and metallothionein (MT) fusion genes ${ }^{1}$, and several lines of mice have now been established in which all of the offspring that inherit the foreign DNA succumb to these tumours at 3-5 months of age (ref. 1 and our unpublished data). Several other tissues, notably thymus and kidney, occasionally also show pathological changes. SV40 large-T antigen protein and messenger RNA are always present in affected tissues at much greater concentrations than in unaffected tissues, suggesting that SV40 early-region genes are preferentially activated in choroid plexus, thymus and kidney and that this activation frequently leads to tumorigenesis in the choroid plexus ${ }^{1}$. To determine which regions of the original constructs are important for this tumorigenesis, we have now tested several derivatives and report here that the large-T antigen is sufficient, that the MT fusion gene is dispensable and 